\title{
CUIDADO A PESSOAS COM TUBERCULOSE PRIVADAS DE LIBERDADE E A EDUCAÇÃO PERMANENTE EM SAÚDE
}

\author{
CARE FOR PEOPLE DEPRIVED OF FREEDOM WITH TUBERCULOSIS \\ AND PERMANENT EDUCATION IN HEALTH
}

\author{
CUIDADO DE PERSONAS CON TUBERCULOSIS PRIVADAS DE \\ LIBERTAD Y LA EDUCACIÓN PERMANENTE EN SALUD
}

\author{
Vanessa Cristina Neves Fabrini ${ }^{1}$ \\ Brígida Gimenez Carvalho ${ }^{2}$ \\ Fernanda de Freitas Mendonça ${ }^{3}$ \\ Maria Helena Dantas Guariente ${ }^{4}$
}

Resumo A tuberculose é um dos principais agravos a ser enfrentado no mundo, e a alta incidência na população privada de liberdade (904,9/100 mil habitantes, em 2013) contribui para a dimensão do problema. Este estudo apresenta a análise baseada em pesquisa-ação, desenvolvida em uma intervenção institucional que usou a Educação Permanente em Saúde para reorganização do cuidado prestado às pessoas com tuberculose e privadas de liberdade. Participaram da pesquisa os trabalhadores de enfermagem de uma penitenciária do Paraná, por meio de sete oficinas de Educação Permanente em Saúde. Três delas tematizaram o trabalho em equipe, acolhimento e corresponsabilidade; em outras duas, discutiram-se aspectos atuais da doença, a prática de cuidado desenvolvida e uma nova proposta de trabalho foi construída pela equipe. As duas últimas monitoraram a proposta implantada e corrigiram falhas. A pesquisa-ação articulada à Educação Permanente em Saúde mostrou-se apropriada ao desenvolvimento da intervenção, possibilitou a mudança de práticas dos trabalhadores e a transformação do cuidado às pessoas com tuberculose na instituição.

Palavras-chave assistência de enfermagem; educação permanente; pessoas privadas de liberdade; tuberculose.

\begin{abstract}
Tuberculosis is one of the main grievances to be combated throughout the world, and the high incidence among the population that is deprived of freedom (904.9/100 thousand inhabitants, in 2013) contributes to increase the dimension of the problem. This study presents the analysis based on action research, which was developed through an institutional intervention that used Ongoing Education in Health to reorganize the care provided to those deprived of freedom who have tuberculosis. The participants of the research were the nursing workers at a penitentiary in the state of Paraná, Brazil; the workers participated in seven Ongoing Education in Health workshops. Three of the workshops were on team work, user embracement and joint responsibility; two other workshops discussed the current aspects of the disease, the care practice developed, and a new work proposal was established by the team. The last two workshops monitored the implemented proposal and corrected mistakes. The action research combined with the Ongoing Education in Health was adequate regarding the development of the intervention, and enabled the change in the practices of the workers and the transformation of the care for people with tuberculosis in that institution.
\end{abstract}

Keywords nursing assistance; permanent education; people deprived of freedom; tuberculosis. 


\section{Introdução}

A tuberculose (TB) é um dos principais agravos de saúde a ser enfrentado no mundo. Em 2013, o Brasil ocupava a $16^{a}$ posição entre as 22 nações responsáveis por $80 \%$ dos casos de tuberculose no mundo, sendo a população privada de liberdade (PPL) um grupo que contribuiu para a posição do país neste ranking.

Em 2013, a PPL representava 0,3\% da população brasileira, contribuindo, no entanto, com 7,8\% dos casos novos de TB notificados no país (Brasil, 2013). A taxa de incidência registrada na PPL foi, aproximadamente, 16 vezes superior a da população geral no ano de 2007 e 25 vezes superior em 2013 (de 627,6 e 904,9 casos por 100 mil indivíduos em 2007 e 2013, respectivamente) (Macedo, Maciel e Struchiner, 2017).

As condições de encarceramento favorecem a transmissão da TB e a alta frequência dos doentes que ingressam no sistema penitenciário propicia a proliferação intramuros. A incidência na PPL é muito elevada, 23 vezes superior a da população em geral, conforme dados do Programa Nacional de Controle da Tuberculose. Esta alta incidência coloca em situação de risco as comunidades de origem dos presos e, por conseguinte, toda a sociedade livre, fortalecendo a cadeia de transmissão por meio do contato com familiares e servidores do sistema penitenciário (Brasil, 2011).

Com vistas a reduzir este indicador de incidência de TB na PPL, é proposto que a assistência de saúde relacionada à tuberculose prevista na Legislação da Saúde no Sistema Penitenciário (LSSP) seja implementada em todos os presídios. A LSSP é uma proposta da Saúde do Sistema Penitenciário (Sispe) vinculada ao Ministério da Saúde (MS), cujo intuito é contribuir para a gestão do Plano Nacional de Saúde no Sistema Penitenciário (PNSSP) em parceria com o Departamento Penitenciário Nacional, do Ministério da Justiça. O PNSSP foi criado com o objetivo de que as ações e serviços de saúde no sistema penitenciário fossem organizados tendo como base os princípios do Sistema Único de Saúde (SUS) (Brasil, 2010).

Contudo, após 10 anos de avaliação do PNSSP, constatou-se o esgotamento deste modelo, que se mostrou restrito por não contemplar em suas ações, entre outras coisas, a totalidade do itinerário carcerário - delegacias e distritos policiais, cadeias públicas, colônias agrícolas ou industriais e, tampouco, penitenciárias federais (Brasil, 2014).

Deste modo, em 2014, o MS lançou a Política Nacional de Atenção Integral à Saúde das Pessoas Privadas de Liberdade no Sistema Prisional (PNAISP), com o objetivo de ampliar as ações de saúde do SUS para a PPL, fazendo com 
que cada unidade básica de saúde prisional passasse a ser visualizada como ponto de atenção da Rede de Atenção à Saúde (Brasil, 2014).

Embora a formulação de políticas e protocolos possa contribuir para realizar um bom trabalho, estes nem sempre estão atualizados frente à rapidez com que os modos de trabalhar se transformam (Educação Permanente em Saúde em Movimento, 2014), ou mesmo não se aplicam à realidade vivenciada nos diferentes serviços.

Desta forma, é fundamental que as realidades cotidianas do mundo do trabalho possam ser reconhecidas como problemáticas pelos trabalhadores que nele atuam e se constituam como o 'meio' do processo pedagógico e de aprendizagem do trabalhador com o seu próprio agir produtivo (Feuerwerker, 2014). Ou seja, a aposta é que a educação permanente em saúde (EPS) seja uma das mais potentes ferramentas para mudar a realidade de atenção à saúde, em que o fazer é posto sob análise e intervenção, colocando "em foco a compreensão e problematização do próprio agir individual e coletivo dos trabalhadores, ali no seu mundo produtivo" (Feuerwerker, 2014, p. 96). Essa concepção revelou a necessidade de rever as práticas assistenciais desenvolvidas por uma equipe de saúde de uma penitenciária para pessoas com TB que se encontravam institucionalizadas.

Como a TB é uma doença emergente, com alta prevalência entre os detentos, é relevante uma ação que modifique as práticas assistenciais e que possa causar impacto nessa situação. Dessa forma, justifica-se este estudo pela contribuição não só para a população carcerária, mas também para seus familiares, servidores do sistema prisional e comunidade em geral.

Assim, este estudo objetiva descrever e analisar uma intervenção institucionalque usou a EPS como estratégia para reordenar o cuidado desenvolvido por uma equipe de enfermagem para detentos de uma Penitenciária Estadual localizada no Norte do Paraná.

\section{Pesquisa-ação e EPS: estratégias de uma intervenção}

Trata-se de um estudo qualitativo descritivo, desenvolvido por meio da pesquisa-ação. Este método ou estratégia de pesquisa se estabelece em uma estrutura coletiva, participativa e ativa na busca de informação. Como método, a pesquisa-ação se comporta diferentemente de outros tipos de pesquisas, pois procura a aquisição do conhecimento durante o processo e a 'transformação', em vez de se preocupar com a explicação dos fenômenos sociais após seu acontecimento (Brandão e Borges 2007). 
A pesquisa-ação foi realizada como atividade de produção de conhecimento e elaboração de uma proposta de intervenção visando à melhoria no atendimento ao prisioneiro com TB.

O planejamento da pesquisa passou por quatro fases (Thiolent, 1997), propostas conforme a organização e pertinência do contexto do sistema penal e as peculiaridades dos participantes. Estas fases foram assim delineadas: 1. Fase exploratória: a equipe detectou o problema e o tipo de ação possível. 2. Fase de pesquisa aprofundada: o problema foi investigado por diversos instrumentos, discutidos e interpretados pelo grupo.

3. Fase da ação: difusão das ações levantadas, definição de objetivos alcançáveis por meio de ações concretas e discussão e definição de propostas negociáveis.

4. Fase de avaliação: fase de observação, de monitoramento da proposta implantada, de redirecionamento do rumo dos acontecimentos, além do resgate do conhecimento produzido no decorrer do processo.

Neste estudo, a pesquisa-ação foi articulada à EPS, que é concebida como um processo em que o cotidiano do trabalho em saúde é colocado em análise, processo este “(...) que se permeabiliza pelas relações concretas que operam realidades e que possibilita construir espaços coletivos para a reflexão e avaliação de sentido dos atos produzidos no cotidiano" (Ceccim, 2005, p. 161).

Foram desenvolvidas sete oficinas de EPS inicialmente com um tema predeterminado e, conforme os sujeitos envolvidos desejassem ou conforme se revelasse necessário, estes temas foram reajustados. Todo o processo aconteceu dentro do horário de trabalho, de acordo com as condições verificadas diariamente pela Divisão de Segurança e Disciplina (DISED) e com a anuência do diretor. As oficinas tiveram duração aproximada de duas horas, ocorreram a cada três semanas, no período de outubro de 2014 a fevereiro de 2015, e foram gravadas em vídeo.

O produto das oficinas foi transcrito integralmente em um caderno de campo e sistematizado em um relatório. Para preservar a identidade dos participantes, suas falas foram codificadas, atribuindo-lhes a letra $\mathrm{P}$ acrescido de um número ordinário (P1, P2..., P7).

Para auxiliar o monitoramento dos resultados, especialmente na fase de avaliação, observaram-se anotações de enfermagem no Registro do Sintomático Respiratório no Serviço de Saúde, além dos prontuários dos prisioneiros com diagnóstico de TB e os prontuários de sintomáticos respiratórios. Observou-se também o caderno de registro criado em uma das oficinas, intitulado "protocolo de tuberculose da Penitenciária Estadual de Londrina (PEL)".

Os participantes manifestaram concordância em participar da pesquisa, após tomarem conhecimento da proposta e assinarem o termo de consentimento livre e esclarecido. 
As oficinas de EPS ocorreram após aprovação do Comitê de Ética e Pesquisa da instituição à qual é vinculada a pesquisadora, sob o n. 809.861. Também foram respeitadas as condições de segurança dos trabalhadores, verificadas pela DISED e a anuência prévia do diretor da Unidade Penal (UP). Este material é resultado de dissertação de mestrado da autora principal e foi financiado com recursos próprios.

\section{A EPS e a reorganização do cuidado às pessoas com tuberculose privadas de liberdade}

Os participantes da pesquisa são os enfermeiros, técnicos e auxiliares de enfermagem, totalizando sete trabalhadores que integram a equipe de enfermagem e atuam no período diurno e noturno. Um enfermeiro do sexo masculino com menos de seis meses de experiência de trabalho na UP; uma enfermeira que desempenha a função na unidade há sete anos; três técnicos de enfermagem que atuam na unidade há quatro anos, e dois que atuam há mais de vinte anos. Todos são maiores de 18 anos e, entre os técnicos, três deles são do sexo masculino e dois, do sexo feminino.

Para fins elucidativos, o processo vivenciado pela equipe de enfermagem para reorganização da atenção à pessoa com TB, na UP estudada, está apresentado seguindo a sistematização das etapas da pesquisa-ação que são: fase exploratória, fase de pesquisa aprofundada, fase de ação e fase de avaliação (Thiolent, 1997).

\section{Fase exploratória}

Na fase exploratória, foram realizadas três oficinas de EPS com o objetivo de refletir sobre a assistência de enfermagem relacionada aos cuidados com a $\mathrm{TB}$ aos detentos e discutir as percepções e interações no trabalho em equipe. Para atingir tal objetivo, contaram-se com dinâmicas de grupo, dramatizações, filmes e discussões. A sistematização das oficinas desta fase está demonstrada no Quadro 1. 


\begin{tabular}{|c|c|c|}
\hline \multicolumn{3}{|c|}{ Sistematização das oficinas de acordo com as estratégias de operacionalização e questões norteadoras. } \\
\hline Oficina & Estratégias & Questões norteadoras \\
\hline \multirow[t]{2}{*}{$\begin{array}{l}\text { Oficina } 1 \\
\text { Trabalho em equipe }\end{array}$} & \multirow[t]{2}{*}{ Filme } & $\begin{array}{l}\text { - Como analisam o resultado da interação das } \\
\text { personagens, dos saberes de cada indivíduo? }\end{array}$ \\
\hline & & $\begin{array}{l}\text { - Que maneiras podem motivar a equipe e o preso com } \\
\text { tuberculose, quanto ao tratamento? }\end{array}$ \\
\hline \multirow{4}{*}{$\begin{array}{l}\text { Oficina } 2 \\
\text { Trabalho em equipe }\end{array}$} & \multirow{4}{*}{$\begin{array}{l}\text { Dinâmica do peixe. } \\
\text { Dramatização }\end{array}$} & - Reflexão sobre o sucesso do tratamento: quem foram \\
\hline & & $\begin{array}{l}\text { os grandes responsáveis? Os profissionais de saúde ou } \\
\text { usuários? }\end{array}$ \\
\hline & & $\begin{array}{l}\text { - Quais as diferenças entre fazer o peixe sozinho e em } \\
\text { grupo? }\end{array}$ \\
\hline & & $\begin{array}{l}\text { - Houve momentos em que foi preciso ceder para alcançar } \\
\text { o objetivo? }\end{array}$ \\
\hline \multirow{2}{*}{$\begin{array}{l}\text { Oficina } 5 \\
\text { Resolvendo conflitos, criando } \\
\text { soluções para o trabalho em } \\
\text { equipe }\end{array}$} & \multirow[t]{2}{*}{ Dinâmica de grupo } & $\begin{array}{l}\text { - Quais as estratégias possíveis para resolução de conflitos } \\
\text { e aperfeiçoamento do trabalho em equipe? }\end{array}$ \\
\hline & & $\begin{array}{l}\text { - Quais habilidades reconhecemos em cada integrante } \\
\text { da equipe? }\end{array}$ \\
\hline
\end{tabular}

A Oficina 1, intitulada "Trabalho em equipe", teve como objetivo proporcionar reflexões sobre o tema relacionado ao trabalho desenvolvido pelos participantes e trazer à tona as relações estabelecidas entre os trabalhadores da enfermagem e os demais profissionais da instituição (agente penitenciário, assistente social e psicólogo). Também objetivou desencadear reflexões sobre o cuidado prestado ao detento doente nas dependências da penitenciária.

Após a apresentação de um filme, algumas questões, tais como a interação e estratégias para a atenção de qualidade à pessoa com tuberculose, foram discutidas com os participantes.

Nas discussões, foi ressaltada pelos participantes a importância dos termos: liderança, trabalho em equipe, humanização, integralidade, fé, confiança, acreditar na cura da doença e sensibilização, como pode ser observado nas falas a seguir:

A tuberculose tem cura, temos que acreditar no tratamento e na cura, há cura e o tratamento tem fim, não é para sempre (P6).

O trabalho em equipe deve focar na conscientização, no cuidado ao paciente (...) (P1).

Como última questão norteadora, foi problematizada: que estratégias podem ser utilizadas para motivar a equipe e o preso com TB, quanto ao tratamento?

As discussões focaram na motivação do preso e do agente penitenciário, porém, não foi mencionada pelos participantes a responsabilidade da equipe de enfermagem quanto ao diagnóstico e tratamento. Foi afirmado que o tratamento e a cura da TB depende da pessoa que está doente, de tomar corretamente os medicamentos. 
A Oficina 2 de EPS, "Trabalho em equipe", deu seguimento às discussões iniciadas no primeiro encontro, esta com enfoque na assistência à tuberculose. A reunião foi dividida em dois momentos. O primeiro momento consistiu em uma dinâmica de grupo que tinha como objetivo "vivenciar a experiência de criação em equipe que promovesse a percepção do fazer em conjunto, da soma das diferenças, guiado por um protocolo de ações" (Brasil, 2009a, p. 73).

No segundo momento, foram realizadas dramatizações envolvendo aspectos da TB, tais como: história da doença, acolhimento, orientações, assistência, encaminhamentos, trabalho em equipe.

Ao final das apresentações foi desencadeada uma discussão norteada pelas dramatizações. Os participantes destacaram dificuldade de relacionamento entre os trabalhadores de turnos diferentes e ausência de comunicação entre eles, conforme ilustra a fala:

(...) fica aquela facção... O pessoal da noite e o pessoal do dia. No caso, eu e o P1 nos conhecemos há muito tempo, mas os demais (...) (P3).

Além disso, o desinteresse em acolher o paciente por parte de uma das equipes, a demora no atendimento e no diagnóstico, pois, segundo um dos participantes,

$\mathrm{O}$ receio do profissional acaba afastando o paciente (P4).

Também foram citados o preconceito contra a doença, as questões familiares e a classificação quanto ao ambiente em que vive o doente (moradores de rua, presidiários etc.). Conforme os participantes,

(...) o paciente acaba sendo classificado pelo ambiente que ele vive (P6).

Apesar das situações pontuadas que demonstraram problemas na atenção ao doente, os participantes consideraram que os atendimentos dramatizados eram organizados e que o profissional de saúde estava capacitado para o atendimento dos pacientes, o que denota certo conformismo com o atendimento prestado.

Assim, os trabalhadores foram questionados quanto ao que poderia ser mudado para qualificar o atendimento. Diante disso, surgiram nas falas: ouvir mais, não centralizar no médico, descentralizar a solicitação do exame, melhorar a abordagem, importar-se com a queixa do paciente. Para um dos participantes

(...) o tratamento descentralizado funciona melhor, pois muitas vezes o paciente não tem como comparecer ao CIDI [Centro Integrado de Doenças Infecciosas] (P4). 
Antes de finalizar esta oficina, os trabalhadores foram indagados quanto à responsabilidade dos profissionais de saúde no sucesso do tratamento, tendo em vista que são eles que orientam e que detectam o problema. A esse respeito, a fala de um integrante representou o pensamento da equipe de enfermagem:

Apesar do nosso papel, da nossa função, o responsável pelo tratamento é o paciente, pois é ele quem toma a medicação e depende dele a cura (P5).

Nesta fase de aproximação com o tema (TB), percebeu-se uma equipe colaborativa, porém, com a não percepção de parte dela quanto às falhas no tratamento e prevenção da doença, responsabilizando unicamente o doente pela eficácia do tratamento e atribuindo a necessidade de motivação a outros profissionais do sistema prisional.

Por conta disso, essa temática voltou a ser discutida na Oficina 5, cujo título foi "Resolvendo conflitos, criando soluções para o trabalho em equipe". Nesta oficina, foram realizadas dinâmicas de grupo com as seguintes questões norteadoras: motivação da equipe; integração, interdependência e sinergia nas relações de trabalho.

Essas atividades oportunizaram o reconhecimento de virtudes e competências de cada um dos membros da equipe, e também deixaram clara a necessidade de organização, cooperação e planejamento para sua execução, elementos fundamentais para o trabalho em equipe.

Após esta oficina, com a equipe mais amadurecida, notou-se uma interação maior, interesse e empenho para que as ações pactuadas fossem implementadas e também se notou a importância de cada participante para alcance do objetivo proposto, pois “(...) se houvesse empenho, concentração, comunicação efetiva conseguiríamos cumprir a meta" (P2), ou seja, reorganizar o cuidado à pessoa com TB na PEL.

\section{Fase de pesquisa aprofundada}

Para esta fase, partiu-se do conhecimento prévio dos participantes, com posterior consulta ao Manual de Recomendações para o Controle da Tuberculose no Brasil (MRCTB) e à LSSP (Brasil, 2010). O Quadro 2 apresenta a sistematização das oficinas. 


Quadro 2
\begin{tabular}{|lll|}
\hline $\begin{array}{l}\text { Sistematização das oficinas da fase de pesquisa aprofundada, de acordo com as estratégias de operacionalização } \\
\text { e questões norteadoras }\end{array}$ & \multicolumn{1}{l|}{ Estratégias } & Questões norteadoras \\
\hline Oficina & Vídeo sobre TB. & $\begin{array}{l}\text { Aspectos históricos, formas de diagnóstico, } \\
\text { tratamento, controle e medidas preventivas da TB }\end{array}$ \\
\hline $\begin{array}{l}\text { Oficina 3 } \\
\text { sobrofundando o conhecimento tuberculose }\end{array}$ & Discussão - MRCTB. & \\
$\begin{array}{l}\text { Oficina 4 } \\
\text { LSSP e elaboração do protocolo }\end{array}$ & Apresentação da LSSP. & $\begin{array}{l}\text { Como sistematizar a atenção e o cuidado à TB para } \\
\text { a PPL? }\end{array}$ \\
\hline
\end{tabular}

A Oficina 3, "Aprofundando o conhecimento sobre tuberculose", teve o objetivo de conhecer o MRCTB (Brasil, 2011). Iniciou-se com a apresentação de um vídeo que explorou aspectos da doença. Após o vídeo, foram distribuídos aos participantes textos do MRCTB para leitura e posteriormente ocorreu a sistematização dos tópicos (detecção, diagnóstico clínico e epidemiológico, exames laboratoriais e de imagem, tratamento, controle dos contatos e medidas preventivas).

Conforme os sujeitos foram apresentando os tópicos por cuja sistematização ficaram responsáveis, evidenciaram-se nas falas a relação com o cotidiano da instituição, a descoberta de procedimentos antes não conhecidos e o engajamento dos participantes na realização da atividade, bem como a ausência de momentos de EPS para atualização de aspectos relacionados ao trabalho.

Faz tempo que não têm (essas oficinas). Na verdade, mais de 10 anos que não tem oficina nenhuma, então, de certa forma, é uma maneira de reciclar, atualizar o pessoal e nos aproximar $(\mathrm{P} 1)$.

A Oficina 4, "Legislação em Saúde no Sistema Penitenciário e elaboração do protocolo", teve como principal meta a construção de uma rotina sistematizada de atendimento ao preso com $\mathrm{TB}$, em que foram descritas atividades de prevenção, diagnóstico e tratamento da doença, de acordo com a realidade vivenciada na Instituição.

Nesta oficina, estudou-se a LSSP para complementação e construção da proposta. Antes da apresentação das normativas contidas nessa legislação, construiu-se um cartaz da rotina de atendimento ao preso com TB na PEL para dar destaque às diferenças entre o que se praticava e o recomendado e também para desencadear uma discussão sobre as possibilidades e necessidades de mudança das práticas.

Nas falas a respeito do fluxo existente, destacaram-se limites na prática do acolhimento ao preso no momento da triagem e até mesmo a negligência para com as queixas dos doentes: 
(...) falou que tem tosse eu meio que ignoro, pois tosse todo mundo diz que tem (P6).

(...) é assim: eles começam a mandar bilhetes todos os dias. 'Ah, porque eu estou com tosse, estou escarrando sangue'. Na verdade, não é que estão escarrando sangue, é que a tosse é seca e irrita as vias aéreas o que acaba machucando e sangrando (P5).

Ainda sobre o fluxo existente, foi mencionada a coleta do escarro e diagnóstico, a relação com o serviço de referência (Centro de doenças infecciosas) e o tratamento supervisionado:

(...) após o diagnóstico, antes a gente coletava nova amostra em 15 dias, agora eu já não sei mais (P2).

A gente tem que ver o preso tomar a medicação, mas nem sempre fazemos isto (P1).

Os participantes também fizeram menção às questões relativas ao isolamento e à alta do tratamento:

(...) se vai ter a resposta da baciloscopia dentro de um mês, o isolamento vai ser de um mês, não é? (P5).

Isola-se somente o preso ou a cela toda? (P6).

Na última consulta ele faz raio-x, colhe escarro e pronto, está liberado (P3).

\section{Fase da ação}

A fase da ação foi iniciada na Oficina 4 (já apresentada no Quadro 3) em que se elaborou uma nova proposta de atendimento sistematizado ao preso com suspeita ou diagnóstico de TB.

Com base na pesquisa da LSSP e no MRCTB, mas considerando a realidade da instituição, estabeleceu-se uma rotina de rastreamento e atendimento ao preso com tuberculose, conforme apresentado na Figura 1. 


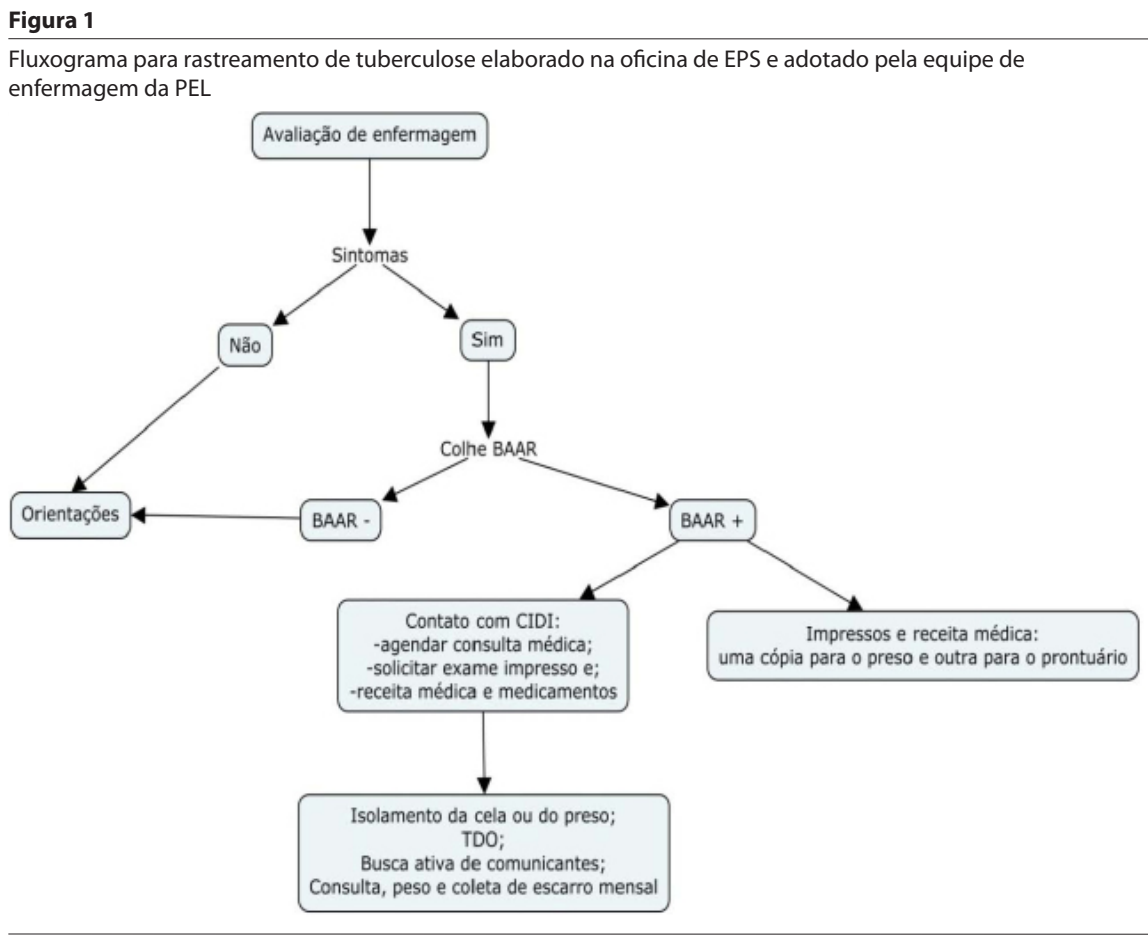

Fonte: Os autores.

O fluxo elaborado marca o início do desenvolvimento de ações que permitem quebrar a cadeia de transmissão da TB. O aspecto mais relevante desta fase foi a execução da ação, da prática, na qual se percebeu o desejo, da maioria, em mudar a realidade na instituição. $\mathrm{O}$ cuidado com a avaliação inicial dos ingressantes foi, sem dúvida, a ação proposta com maior ênfase pela equipe.

Cabe destacar que a equipe reconheceu que a triagem ocorria somente quando os presos eram encaminhados pela equipe de segurança e de maneira aleatória, pois "eu ofereço o teste rápido, mas de tuberculose eu nem lembro. Pergunto se teve, se não, eu já deixo de lado" (P3). Cabe destacar que os trabalhadores reconheceram que a triagem ocorria somente quando os presos eram encaminhados pela equipe de segurança e de maneira aleatória, pois "eu ofereço o teste rápido, mas de tuberculose eu nem lembro. Pergunto se teve, se não, eu já deixo de lado" (P3). O tratamento diretamente observado (TDO) nem sempre ocorria; na maioria das vezes, o tuberculostático era deixado para que os agentes penitenciários entregassem ao preso. Outra constatação feita pela equipe foi a de que desde 2013 até fevereiro de 2015 haviam sido registradas apenas 12 coletas de escarro para baciloscopia.

$\mathrm{O}$ isolamento foi uma das questões de maior debate entre o grupo, devido a várias interpretações sobre o que está descrito na LSSP e no MRCTB, porém, em comum acordo, decidiu-se adaptar o que é proposto na norma à realidade da instituição. 
Para o desenvolvimento de ações, foram pactuadas atribuições específicas para cada trabalhador da equipe, e foi pactuada também a substituição em caso de licenças, atestados ou férias.

\section{Fase de avaliação}

Após o estabelecimento de uma rotina de atendimento, optou-se por fazer uma pausa de um mês entre uma oficina e outra, para melhor avaliação do desenvolvimento das ações. Ocorreram duas reuniões de avaliação com intervalos mensais (Quadro 3).

\begin{tabular}{|c|c|c|}
\hline \multicolumn{3}{|c|}{ Sistematização das oficinas da fase de avaliação } \\
\hline Oficina & Estratégias & Questões norteadoras \\
\hline $\begin{array}{l}\text { Oficina } 6 \\
\text { Avaliando resultados }\end{array}$ & Dinâmica de grupo & $\begin{array}{l}\text { Atribuições e responsabilidades assumidas pelos } \\
\text { trabalhadores da equipe }\end{array}$ \\
\hline & & Quais atividades realizamos do plano de ação? \\
\hline $\begin{array}{l}\text { Oficina } 7 \\
2^{2 a} \text { avaliação do protocolo }\end{array}$ & Discussão em grupo & O que estamos fazendo e o que podemos melhorar? \\
\hline
\end{tabular}

A Oficina 6 teve como objetivo recordar as ações pactuadas no protocolo. Os cartazes sobre o protocolo, elaborados pela equipe, foram fixados na parede para que, com base neles, fossem apontadas as falhas operacionais, os acertos e as revisões necessárias.

Das ações pactuadas, não estavam sendo desenvolvidas: impressão da lista de ingressos para triagem; os impressos que deveriam ser entregues ao detento com diagnóstico de TB; e as anotações no caderno de protocolo. As demais ações já eram executadas.

Com intervalo de, aproximadamente, um mês, realizou-se a última oficina de EPS. A oficina “O que podemos melhorar?" tinha como objetivo realizar uma segunda avaliação das propostas implantadas ao preso com TB e encerrar o período de coleta de dados.

Nesta reunião, os participantes relataram que todas as atividades propostas estavam sendo executadas. Como finalização da oficina, foi proposta ao grupo uma reunião mensal para discussão, entre outros assuntos, do andamento desta intervenção. A proposta foi aceita pela equipe com satisfação. Outro participante propôs reuniões periódicas de EPS com temas variados, em que cada participante instruiria um determinado assunto, o que também foi aceito pelo grupo.

Nesta oficina, os participantes relataram satisfação, pois “(...) podemos não ter cumprido tudo, mas estamos nos esforçando (...)" (P6), e demonstraram 
que “(...) o esforço de todos aqui é notável e, o mais importante que vejo, é que todos têm vontade" (P2).

Por fim, a EPS mostrou-se estratégia efetiva na reorganização do cuidado, além de oportunizar momentos de encontros e trocas entre os trabalhadores, como explicitado nas falas:

(...) eu achei estas oficinas muito boas, foi muito bom reaprender e seria muito bom termos mais oficinas como esta. E também, aqui podemos nos encontrar mais com o pessoal da noite e isto serviu até para nos deixar mais unidos. Acho que seria ótimo continuarmos com elas (P1).

Foi muito bom falarmos da TB, pois muita coisa eu já tinha esquecido. Os esquemas de tratamento mudaram, tudo ficou mais moderno. Podemos falar de HIV/ Aids numa próxima ou de hanseníase já que temos um preso com hanseníase agora (...) (P4).

Todo o processo fez com que os participantes passassem a desejar uma reorganização da assistência de enfermagem ao preso com TB. Incluir ações como pesagem do preso, oferta de teste rápido, sinais vitais e questões específicas sobre sintomatologia e antecedentes da patologia fez com que os participantes se sentissem como investigadores à procura de qualquer vestígio; e descobrir um potencial doente foi como um trunfo para os sujeitos da pesquisa. Ao final das oficinas, verificou-se o aumento do número de solicitações de baciloscopias e vigilância no tratamento, o que repercutiu em aumento de doentes diagnosticados e tratados na UP.

\section{Reflexões sobre a intervenção}

Os resultados demonstraram que os trabalhadores pesquisados não se constituíam em uma equipe de trabalho integrada, e sim em um agrupamento de pessoas que atuavam num mesmo local, de forma acomodada, desanimada e com ausência de momentos conjuntos de discussão e de qualificação sobre o trabalho que desenvolviam.

Para Fortuna et al. (2005, p. 267), “falar de trabalho em equipe não é falar de algo harmonioso. É falar de pessoas em relação, que terão momentos de conflitos", visto que o trabalho em saúde constitui-se em atividade produtora de estresse. Isso se deve às condições de trabalho muitas vezes inadequadas, à especificidade do cuidado nos serviços de saúde, às exigências da atividade e ao não reconhecimento do trabalho, especialmente no setor público (Oliveira e Araújo, 2018), e ainda mais em uma penitenciária. Para estas autoras, “as condições de trabalho inadequadas intensificam o esforço realizado que, não 
condizente com a recompensa [...], terminam por repercutir no padrão de motivação do trabalhador, na sua satisfação com o trabalho"(p.245).

Para superar a dificuldade do trabalho em equipe, há necessidade de se trabalhar a grupalidade (para que as equipes se constituam como grupos e não agrupamentos), instituindo espaços (reuniões) entre os trabalhadores, com lugar e tempo definidos. Isso possibilita ampla discussão e apropriação sobre o trabalho produzido e também se constitui em condição essencial para o desenvolvimento da EPS.

Autores consideram que a EPS é a mais apropriada ferramenta educativa para produzir mudanças na prática, pois propicia a reflexão na ação e fortalece o trabalho em equipe (Ceccim, 2005; Carotta, Kawamura e Salazar, 2009; Davini, 2009).

Neste sentido, a EPS teve o poder de facilitar o envolvimento da equipe e proporcionar a articulação entre os sujeitos, propiciando troca de saberes, reflexões sobre práticas e, consequentemente, melhoria no processo de trabalho.

Nesse estudo, a convergência entre a metodologia de pesquisa escolhida, a pesquisa-ação, e o referencial teórico que orientou a construção das oficinas, a EPS, foi essencial para o alcance do objetivo proposto: reordenar o cuidado à PPL com tuberculose em uma penitenciária. Ambos se dão no cotidiano do trabalho e sua construção coletiva, tanto no desenvolvimento quanto na apropriação dos resultados, foi essencial para a transformação das práticas dos envolvidos.

A Política Nacional de Educação Permanente em Saúde (PNEPS), instituída em 2004, e reformulada por meio da portaria n. 1996 de 2007, foi instituída como estratégia do SUS para a formação e o desenvolvimento de trabalhadores para o setor (Brasil, 2004; 2007). Com o dever primordial de congregar, articular e integrar os profissionais de saúde, a PNEPS tem o objetivo de conduzir a melhoria dos sistemas locais de saúde, sejam eles hospitais, unidades básicas de saúde ou presídios.

Foi condição indispensável nesta intervenção, para que os trabalhadores realizassem mudanças em suas práticas, o incômodo e a percepção de que a maneira vigente de fazer ou pensar era insuficiente ou insatisfatória para dar conta dos desafios do trabalho no cotidiano. Esse incômodo ou percepção de insuficiência teve que ser intenso, não tendo sido produzido mediante análises externas, mas com base no vivido e percebido pelos próprios trabalhadores (Feuerwerker, 2014).

No início do processo, os participantes reconheciam como deveria ser a abordagem ao preso com TB, pois destacaram a importância da humanização durante o tratamento. Porém, se mostraram pouco permeáveis ao problema e contraditórios ao atribuírem responsabilidade exclusiva do usuário pelo sucesso ou insucesso do tratamento. Estudos com doentes crônicos também têm concluído que, para os trabalhadores, o sucesso do tratamento é extre- 
mamente dependente do comportamento dos doentes (Wendling, Modena e Schall, 2012; Fraga, 2006; Gastaldo, 1996; Petersen e Lupton, 1996).

Entretanto, ao responsabilizar apenas os pacientes pelo seu estado de saúde e refletir a respeito dessa concepção, a equipe passou a repensar o seu papel de promotora da saúde e sobre o quanto estava descumprindo os objetivos dos programas de saúde. Nesse aspecto, a EPS se mostrou potente para provocar a reflexão acerca dos problemas vivenciados no cotidiano e sobre seu papel no enfrentamento deles. Possibilitou a ruptura da dicotomia entre teoria e prática por meio da inversão da relação conteúdo teórico-vivência, fazendo com que as vivências fossem as ordenadoras do processo de aprendizagem dos conteúdos teóricos. A capacidade de trazer para a cena o vivido possibilitou desterritorializar, criando possibilidades de novas construções subjetivantes (Merhy, 2013).

A culpabilização do doente deve ser combatida, oferecendo subsídios para o enfrentamento da vulnerabilidade desta população, já em situação de exclusão social. Quanto ao conjunto equipe de enfermagem/usuário (neste caso, especificamente, o detento), é necessário rever posições e abrir-se à possibilidade de coprodução e cogestão a fim de que se efetive o plano de ação terapêutica com corresponsabilidade entre os sujeitos (Brasil, 2013) (e aqui, chamamos de sujeitos tanto a equipe como o usuário).

Outra questão evidenciada pelos resultados foram as limitações relativas ao acolhimento/triagem realizada pela equipe de saúde. A EPS é uma estratégia fundamental para despertar nos trabalhadores esses limites presentes no processo de trabalho. Contudo, vale ressaltar que, quando se trata do ambiente prisional brasileiro, o qual se encontra em condições de extrema precariedade seja pela superlotação, pelas péssimas condições estruturais e pela quantidade incipiente da força de trabalho em saúde (Freitas et al., 2016; Martins et al., 2014), é preciso flexibilizar e compreender que ações isoladas de EPS dificilmente suprirão essas limitações.

Além dos desafios já apontados, o estudo de Souza e Passos (2008) revelou que a presença do agente penitenciário dificulta a autonomia do profissional de enfermagem. Segundo Sánchez, Larouzé e Diuana (2010) quando as unidades prisionais possuem programas de controle à TB são, em geral, verticais, prescritivos e mal inseridos nas redes de saúde extramuros os quais, em alguns locais, estabelecem cotas para o sistema penitenciário, limitando o acesso à baciloscopia. Talvez seja essa uma das razões que explica o fato de que foram realizadas apenas 12 baciloscopias de 2013 até fevereiro de 2015.

Tal realidade reforça ainda mais a necessidade de implementação da PNAISP (Brasil, 2014) a qual, além de inserir uma equipe da Estratégia Saúde da Família no sistema penitenciário, propõe também ações de vigilância sanitária e epidemiológica e incentivo às ações de educação em saúde, voltadas tanto para trabalhadores (EPS) quanto para a PPL. Isso possibilitaria que a unidade 
prisional deixasse de ser um ponto de atenção isolado no sistema de saúde e passasse a integrar a rede de atenção.

Para Ferraz (2015), o avanço da assistência à saúde no sistema prisional tem se dado de forma lenta e desproporcional, talvez pelo fato de a adesão à PNAISP ser facultativa. Destaca-se ainda que, diante do sucateamento e deterioração dos espaços prisionais, o valor do incentivo repassado à saúde no Sistema Prisional é irrisório, não estimulando a adesão de estados e municípios.

Sobre a aproximação com o tema da TB, apesar de os trabalhadores terem se mostrado desatualizados quanto ao protocolo instituído para diagnóstico e tratamento da doença, percebeu-se nas apresentações o quanto os participantes fizeram relação com o que vivenciavam no cotidiano do trabalho. Esta questão está relacionada a um dos conceitos-chave da EPS: a aprendizagem significativa.

Para que ocorra a aprendizagem significativa, faz-se necessário conhecer previamente o que o aprendiz já sabe e estimular a construção de um novo conhecimento ancorado ao conhecimento prévio (Freire, 1996; Luckesi, 2003). A esse respeito, Feuerwerker (2014) destaca que

(...) uma informação ou experiência pedagógica somente produz sentido quando dialoga com toda a acumulação anterior que os trabalhadores trazem. Partir dos incômodos, dialogar com o acumulado e produzir sentido: essas são as chaves para a aprendizagem significativa (Feuerwerker, 2014, p. 97).

Durante o processo de construção da proposta de ação, verificou-se que, ao olharem para a própria prática, os trabalhadores tornaram-se capazes de enxergar limites que na fase inicial das oficinas não eram percebidos, tais como: negligência, medicação não administrada, entre outros. A EPS desvelou nestes sujeitos o processo de trabalho vivido, fazendo com que se colocassem em análise, o que gerou incômodo e desnaturalizou os problemas do processo de trabalho.

Contudo, alguns estudos ainda apontam a EPS como um processo de caráter pontual, caracterizado por metodologias de transmissão de conhecimento, nas quais a participação do trabalhador é praticamente inexistente (Peres, Silva e Barba, 2016; Silva et al., 2016). Quando estruturadas dessa maneira, tais ações se caracterizam como ações de educação continuada, cujo propósito, de fato, é promover capacitação e treinamento da equipe (Ribeiro e Motta, 2006).

Nas oficinas avaliativas, evidenciou-se o quanto os sujeitos tornaram-se protagonistas de ação, algo fundamental ao comprometimento com o trabalho e tão valorizado pela EPS. A definição da EPS disposta pela PNEPS ficou evidente durante esse processo, pois o aprender e o ensinar se incorporaram no cotidiano e transformaram as práticas profissionais (Brasil, 2007; 2009b). 
Diante disso, verifica-se o quanto é fundamental aproximar as pesquisas de EPS ao processo de trabalho em saúde. Segundo pesquisa realizada por Figueiredo et al. (2017), a concentração de estudos (teses e dissertações) sobre a temática EPS, no período de 2004 a 2013, tiveram, majoritariamente, como foco o campo das políticas de saúde, sendo poucos os estudos que aproximaram esse tema do cotidiano do trabalho em saúde. Aproximar a EPS do cotidiano do trabalho é fundamental, no intuído de fortalecer a ideia de que a EPS não necessariamente depende de uma política, mas do movimento dos trabalhadores em colocar o processo de trabalho em análise.

\section{Conclusão}

A EPS foi empregada de modo apropriado para promover a discussão, entre os trabalhadores, sobre seu processo de trabalho, envolvendo a prevenção, controle e tratamento da TB. Por meio de metodologias ativas, as oficinas de EPS foram os cenários em que, além de se discutir e enfrentar a problemática (o cuidado aos presos com TB) abordou-se também o trabalho em equipe.

A estrutura arquitetônica inadequada dos presídios - que dificulta a ventilação e, consequentemente, facilita a transmissão do bacilo - e a morosidade jurídica para a concessão de sentenças ou formas alternativas de cumprimento da pena -, que não o encarceramento em regime fechado -, que contribui para a superlotação das prisões, são também responsáveis pela manutenção dos altos coeficientes da doença. Dessa forma, ações isoladas de EPS não serão suficientes para a mudança desse cenário.

Reconhece-se como limitação deste estudo o fato de ter sido realizado em apenas uma UP, com uma única equipe de enfermagem. Apesar disso, ao serem analisadas as realidades das demais unidades prisionais do Estado, pode-se inferir que esta não é muito distinta das demais, tanto em termos de capacitação profissional quanto em relação às condições a que estão submetidos os detentos.

Conclui-se que a pesquisa-ação articulada com a EPS, usada como estratégia para o enfrentamento do problema da tuberculose na instituição em estudo, conseguiu gerar mudanças de práticas na equipe de enfermagem e transformar a realidade, pois sensibilizou a equipe para a readequação dos cuidados de enfermagem aos presos com tuberculose. Colocar uma ação do cotidiano em pauta, como é um dos pressupostos da pesquisa-ação e da EPS, foi o ponto que despertou e motivou a participação da equipe e a transformação de suas práticas. 


\section{Colaboradores}

Todas as autoras contribuíram igualmente para elaboração do artigo.

Resumen La tuberculosis es uno de los principales problemas de salud a enfrentar en el mundo y la alta incidencia en la población privada de libertad (904,9/100 mil habitantes, en el 2013) contribuye a la magnitud del problema. Este estudio presenta el análisis con base en una investigación-acción, desarrollada en una intervención institucional que usó la Educación Permanente en Salud para reorganizar la atención brindada a las personas con tuberculosis y privadas de libertad. Participaron de la investigación los trabajadores de enfermería de una prisión del estado de Paraná, por medio de siete talleres de Educación Permanente en Salud. En tres de ellas se tematizó el trabajo en equipo, recepción y corresponsabilidad; en otras dos se discutieron aspectos actuales de la enfermedad, la práctica de atención desarrollada y se elaboró una nueva propuesta de trabajo por parte del equipo. En las últimas dos se supervisó la propuesta implantada y se corrigieron errores. La investigación-acción articulada a la Educación Permanente en Salud se mostró apropiada al desarrollo de la intervención, posibilitó el cambio de prácticas de los trabajadores y la transformación de la atención de las personas con tuberculosis en la institución.

Palabras clave asistencia de enfermería; educación permanente; personas privadas de libertad; tuberculosis.

\section{Notas}

${ }^{1}$ Secretaria de Justiça e da Cidadania do Estado do Paraná, Departamento Penitenciário, Penitenciária Estadual de Londrina, Londrina, Paraná, Brasil.

<vanessanfabrini@gmail.com>

Correspondência: Rua Chile, n. 43, CEP 86010-220, Centro, Londrina, PR, Brasil.

${ }^{2}$ Universidade Estadual de Londrina, Centro de Ciências da Saúde, Programa de PósGraduação em Saúde Coletiva, Londrina, Paraná, Brasil.

<brigidagimenez@gmail.com>

${ }^{3}$ Universidade Estadual de Londrina, Centro de Ciências da Saúde, Departamento de Saúde Coletiva, Londrina, Paraná, Brasil.

$<$ fernanda0683@gmail.com>

${ }^{4}$ Universidade Estadual de Londrina, Centro de Ciências da Saúde, Departamento de Enfermagem, Londrina, Paraná, Brasil.

$<$ mhguariente@gmail.com> 


\section{Referências}

BRANDÃO, Carlos R.; BORGES, Maristela C. A pesquisa participante: um momento da educação popular. Revista de Educação Popular, Uberlândia, v. 6, n. 1, p. 51-62, jan./dez. 2007. Disponível em: <http://www.seer.ufu.br/index. php/reveducpop/article/view/19988/10662>. Acesso em: 1 mar. 2015.

BRASIL. Ministério da Saúde. Portaria n. 198/ GM/MS, de 13 de fevereiro de 2004. Institui a Política Nacional de Educação Permanente em Saúde como estratégia do Sistema Único de Saúde para a formação e o desenvolvimento de trabalhadores para o setor e dá outras providências. Diário Oficial [da] República Federativa do Brasil, Brasília, 13 fev. 2004. Seção 1, p. 37-41.

BRASIL. Ministério da Saúde. Ato Portaria GM n. 1.996, de 20 de agosto de 2007. Dispõe sobre as diretrizes para a implementação da Política Nacional de Educação Permanente em Saúde e dá outras providências. Brasília, 2007. Disponível em:<http://bvsms.saude.gov.br/ bvs/saudelegis/gm/2007/prt1996_20_08_2007. html>. Acesso em 15 fev. 2018.

BRASIL. Ministério da Saúde. Secretaria de Atenção à Saúde. Departamento de Ações Programáticas Estratégicas. Área Técnica de Saúde da Criança e Aleitamento Materno. Rede amamenta Brasil: caderno do tutor. Brasília: Ministério da Saúde, 2009a.

BRASIL. Ministério da Saúde. Secretaria de Gestão do Trabalho e da Educação na Saúde. Departamento de Gestão da Educação em Saúde. Política Nacional de Educação Permanente em Saúde. Brasília: Ministério da Saúde, 2009b.

BRASIL. Ministério da Saúde. Secretaria de Atenção em Saúde. Departamento de Ações Programáticas Estratégicas. Legislação em saúde no sistema penitenciário. Brasília: Ministério da Saúde, 2010.

BRASIL. Ministério da Saúde. Secretaria de Vigilância em Saúde. Manual de recomendações para o controle da tuberculose no Brasil. Brasília: Ministério da Saúde, 2011.
BRASIL. Ministério da Saúde. Secretaria de Vigilância em Saúde. Boletim Epidemiológico, Brasília, v. 44, n. 2, 13 p., 2013. Disponível em: <http://funed.mg.gov.br/wp-content/uploads/2014/06/Boletim_Tuberculose_PNCT_2014. pdf>. Acesso em: 6 mar. 2015.

BRASIL. Ministério da Saúde. Política Nacional de Atenção Integral à Saúde das Pessoas Privadas de Liberdade no Sistema Prisional. 2014. Disponível em: <http://dab.saude. gov.br/portaldab/pnaisp.php $>$. Acesso em: 15 fev. 2017.

CAROTTA, Flavia; KAWAMURA, Débora; SALAZAR, Janine. Educação permanente em saúde: uma estratégia de gestão para pensar, refletir e construir práticas educativas e processos de trabalhos. Saúde e Sociedade, São Paulo, v. 18, n. 1, p. 48-51. 2009. Disponível em: <http://www.scielo.br/ scielo.php?script $=$ sci_arttext $\&$ pid $=$ S0104$12902009000500008 \& \operatorname{lng}=\mathrm{en}>$. Acesso em: 11 dez. 2015.

CECCIM, Ricardo B. Educação permanente em saúde: desafio ambicioso e necessário. Interface: Comunicação, Saúde e Educação, Botucatu, v. 9, n.16, p.161-77, set. 2004/fev.2005. Disponível em: <http://www.scielo.br/pdf/icse/v9n16/ v9n16a13.pdf $>$. Acesso em: 30 maio 2014.

DAVINI, Maria C. Enfoques, problemas e perspectivas na educação permanente dos recursos humanos de saúde. In: BRASIL. Ministério da Saúde. Política Nacional de Educação Permanente em Saúde. Brasília: Ministério da Saúde, 2009. p. 39-63.

\section{EDUCAÇÃO PERMANENTE EM SAÚDE EM} MOVIMENTO. Educação e trabalho em saúde: a importância do saber da experiência. 2014. Disponível em: <http://eps.otics.org/material/ entrada-textos/educacao-e-trabalho-em-saude-aimportancia-do-saber-da-experiencia $>$. Acesso em: 12 jul. 2016.

FERRAZ, Eliziane. A Política Nacional de Atenção Integral à Saúde no Sistema Prisional: uma experiência em Serviço Social na Perspectiva 
da Reintegração Social. 2015. 100 f. Trabalho de Conclusão de Curso (Graduação em Serviço Social) - Universidade Federal do Rio Grande do Sul, Porto Alegre, 2015.

FEUERWERKER, Laura C. M. Micropolitica e saúde: produção do cuidado, gestão e formação. Porto Alegre: Rede Unida, 2014. 174p.

FIGUEIREDO, Eluana B. L. et al. Dez anos da Educação Permanente como Política de Formação em Saúde no Brasil: um estudo das teses e dissertações. Trabalho, Educação e Saúde, Rio de Janeiro, v. 15, n. 1, p.147-162, 2016.

FORTUNA, Cinira M. et al. O trabalho de equipe no programa de saúde da família: reflexões a partir de conceitos do processo grupal e de grupos operativos. Revista Latino-Americana Enfermagem, São Paulo, v. 13, n. 2, p. 262268, mar.-abr. 2005.

FRAGA, Alex B. Promoção da vida ativa: nova ordem físico-sanitária na educação dos corpos contemporâneos. In: BAGRICHEVSKY, Marcos; PALMA, Alexandre; ESTEVÃO, Adriana. A saúde em debate na Educação Física. Blumenau: Nova Letra, 2006. p. 105-118. (Volume 2).

FREIRE, Paulo. Pedagogia da autonomia: saberes necessários à prática educativa. 25. ed. São Paulo: Paz e Terra; 1996.

FREITAS, Rosane S. et al. Política Nacional de Atenção Integral à Saúde das Pessoas Privadas de Liberdade no Sistema Prisional: uma análise do seu processo de formulação e implantação. Revista de Políticas Públicas, São Luís, v. 20, n.1, p.171-184, jan.-jun. 2016.

GASTALDO, Denise M. Is health education good for you? The social construction of health education in the Brazilian national health system.1996. (Tese). University of London, Londres, 1996.

LUCKESI, Cipriano. Avaliação da aprendizagem na escola: reelaborando conceitos e recriando a prática. Salvador: Malabares, 2003.

MACEDO, Laylla; MACIEL, Ethel L. N.; STRUCHINER, Claudio J. Tuberculose na população privada de liberdade do Brasil, 2007-2013. Epidemiologia e Serviços de Saúde, Brasília, v. 26, n. 4, p. 783-794, 2017.

MARTINS, Élida L. C. et al. O contraditório direito à saúde de pessoas em privação de liberdade: o caso de uma unidade prisional de Minas Gerais. Saúde e Sociedade, São Paulo, v. 23, n. 4, p.1.222-1.234, 2014.

MERHY, Emerson E. Educação Permanente em movimento: uma política de reconhecimento e cooperação, construindo encontros no cotidiano das práticas de saúde. Porto Alegre, maio de 2013. Disponível em: <http://eps. otics.org/material/entrada-outras-ofertas/ artigos/ep-uma-politica-de-reconhecimentoe-cooperacao-construindo-encontros-nocotidiano-das-praticas-de-saude $>$. Acesso em:15 fev. 2018

OLIVEIRA, Ana M. N.; ARAÚJO, Tânia M. Situações de desequilíbrio entre esforçorecompensa e transtornos mentais comuns em trabalhadores da atenção básica de saúde. Trabalho, Educação e Saúde, Rio de Janeiro, v. 16, n. 1, p. 243-262, abr. 2018.

PERES, Cristiane; SILVA, Roseli F.; BARBA, Patrícia C. S. D. Desafios e potencialidades do processo de educação permanente em saúde. Trabalho, Educação e Saúde, Rio de Janeiro, v. 14, n. 3, p. 783-801, 2016.

PETERSEN, Alan; LUPTON, Deborah. The New Public Health: health and self in the age of risk. London: Sage Publications, 1996.

RIBEIRO, Eliana C. O.; MOTTA, José I. J. Educação Permanente como estratégia na reorganização dos serviços de saúde. Disponível em: < http://www.saude.pr.gov.br/eepp>. Acesso em: 1 abr. 2016

SÁNCHEZ, Alexandra R.; LAROUZÉ, Bernard; DIUANA, Vilma. Controle de tuberculose nas prisões brasileiras: novas abordagens para um antigo problema. Cadernos de Saúde Pública, Rio de Janeiro, v. 26, n. 5, p. 850-851, 2010.

SILVA, Luiz A. A. et al. Avaliação da Educação Permanente no processo de trabalho em 
Saúde. Trabalho, Educação e Saúde, Rio de Janeiro, v. 14, n. 3, p. 765-781, set.-dez. 2016.

SOUZA, Mônica O. S.; PASSOS, Joanir P. A prática de enfermagem no sistema penal: limites e possibilidades. Escola Anna Nery, Rio de Janeiro, v. 12, n. 3, set. 2008.

THIOLLENT, Michel. Pesquisa-ação nas organizações. São Paulo: Atlas, 1997.

WENDLING, Ana P. B.; MODENA, Celina M.; SCHALL, Virgínia T. O abandono do trata- mento da tuberculose sob a perspectiva dos gerentes de diferentes centros de saúde de Belo Horizonte-MG, Brasil. Texto e Contexto Enfermagem, Florianópolis, v. 21, n. 1, p. 77-85, jan.-mar. 2012.

Recebido em 17/10/2017.

Aprovado em 13/03/2018. 